\title{
Jography: exploring meanings, experiences and spatialities of recreational road-running
}

\author{
Simon Cook* \\ Department of Geography \\ Royal Holloway, University of London \\ Egham \\ Surrey TW20 0EX \\ UK \\ Simon.Cook.2013@live.rhul.ac.uk
}

Jon Shaw

School of Geography, Earth and Environmental Sciences

Plymouth University

Drake Circus

Plymouth PL4 8AA

UK

jon.shaw@plymouth.ac.uk

Paul Simpson

School of Geography, Earth and Environmental Sciences

Plymouth University

Drake Circus

Plymouth PL4 8AA

UK

paul.simpson@plymouth.ac.uk

* Corresponding author: Simon.Cook.2013@live.rhul.ac.uk 


\begin{abstract}
Jogging is a relatively under-researched mobile practice with much existing literature focusing on 'serious' and competitive running. In this paper we provide an account of some of the movements, meanings and experiences that together help produce the practice of jogging in the southwestern English city of Plymouth. Drawing upon participant diaries and interviews, we uncover rich detail about how joggers ascribe not one but a number of meanings to their practice. Some of these are positive, some are negative; some complement each other and some compete with each other. We also consider how the experiences of joggers can be shaped by their ongoing need to develop tactics capable of enabling them to negotiate space with non-joggers. This is in some contrast to more competitive running that occurs in the separated space of an athletics track. Our sense is that better awareness of the meanings and experiences of jogging will be of value if the advertised health and sustainability benefits of the practice are to be more effectively encouraged and promoted.
\end{abstract}

Key Words: Running, Jogging, Experience, Meaning, Movement, Mobility

9,802 words excluding title page, abstract, footnotes, captions and reference list. 


\section{Warming up}

In some ways, recreational running - or 'jogging'1, as it is commonly known - can be seen to be a rather pointless form of mobility. The basic signifier of mobility, getting from point $A$ to

point $B$, involves a displacement act entailing movement between two locations (Cidell 2014; Cresswell 2006). This can be seen in Figure 1, which shows a jogging route recorded on MapMyRun taken by an individual through the southwestern English city of Plymouth. The point of mobility here, as is so often the case, is to get from one point in space (i.e. the home) to another (i.e. work) to facilitate the carrying out of an activity at the destination point. Yet Figures 2-4 demonstrate something else. Whether taking the form of the loop (Figure 2), the lollipop (Figure 3) or the out-and-back (Figure 4), the start and finish, point A and point B, are the same for these individuals' runs (see Bissell 2013). The mobile subject here would reach the final destination whether the run was undertaken or not. There is no point $\mathrm{B}$. The purpose of displacement shifts, in that the 'point' is not to get somewhere or do something at the point of arrival; the point is the mobility itself. This sort of pointless movement - both in terms of displacement and purpose - is extremely commonplace in recreational running and is one aspect that perhaps sets this mobile practice apart from many others. Joggers here are mobile just to be mobile, deriving utility from the act of being mobile itself rather than moving to get somewhere and do something there. It is equivalent to so-called 'undirected travel' in the transport literature (see Cao, Mokhtarian, and Handy 2009). Jogging's pointlessness in this dual sense orientates us away from origin and destination and towards the qualities of the journey itself.

\section{FIGURES 1-4 HERE}

Looking at a broader set of 65 mapped runs drawn from the practice of 12 joggers (Figure 5), it is also apparent that, despite the freedom that 'pointless' movement gives in terms of route taken, joggers' movements can still be highly channelled. They are lines on a map. More specifically, they are lines that tend to follow road networks. Figure 5 also demonstrates that our mapped joggers prefer to use the major and main roads of the city to undertake their practice, with a total of 441 occurrences being observed in the runs. In turn, they tended to use smaller roads in order to access major roads, to link major roads, or to add small loops off a major road. They also made relatively little use of pedestrianised routes in the city, perhaps to avoid a greater intensity of encounters with other-space users that can result in a gauntlet-like experience as recounted by Hockey and Allen-Collinson (2007, 2013; see section 5).

\section{FIGURE 5 HERE}


Looking at these figures can tell us quite a lot about, in Cresswell's (2006) terms, the 'brute fact of movement' in relation to this pointlessness. They give a sense of where our participants ran, patterns in their route choice and the sorts of infrastructure they used (or not). Yet at the same time this is a rather simplistic picture of mobility; there is far more to running than the tracing of such lines on a map (Cresswell 2001a). Indeed, Cresswell's more holistic view of mobility is a useful framework for developing sophisticated understandings of such matters. Comprising three entangled facets - movement, meaning and experience this approach to human movement conceives of mobilities as produced (Cresswell 2001b). Developed as a reaction to the chaotic and overly-specific nature of mobilities research hitherto (Blacksell 2005; Cresswell 2006), his framework enables researchers to uncover complex relationships and explore nuanced connections between emerging facets and their associated politics. Indeed, Shaw and Docherty $(2014 a, 32)$ argue that the getting "from anywhere to anywhere in any circumstances is likely to be most insightful and accomplished if it is grounded in a good understanding of all three of Cresswell's triumvirate of movement, experience and representation."

The mobilities turn in the social sciences has brought with it concern for a diverse range of mobile practices. Various studies have considered walking (Middleton 2009), cycling (Spinney 2009), driving (Laurier 2004), train travel (Bissell 2009), bus and coach travel (Jain 2009, 2011) and flying (Adey 2004), among others (see Vannini 2009), from a variety of angles. Perhaps surprisingly given its popularity (Sport England 2013), running as a leisure or recreational activity seems to have eluded sustained or widespread study (Bale 2004). The majority of running literature has tended to focus on 'serious' running or the kind of competitive running that can be quite a demarcated practice (see Allen-Collinson 2003, 2010; Allen-Collinson and Hockey 2001, 2011; Bale 2004; Bale and Sang 1996; Hockey 2004; Hockey and Allen-Collinson 2006, 2013; Lorimer 2012). By contrast, jogging involves the use, and so the sharing, of non-specialised spaces and thus is markedly different from the homogeneous, rationalised and dedicated environment of the track (Bale 1994, 2000, 2003). Further, where recreational running has been researched, there has generally been a focus on quite specific facets: who runners are, where they run in abstract sense (i.e. on the road or in parks), the relationship of running to health and fitness, or reflections on individual (often auto-ethnographic) experiences of running. A more holistic exposition of how bodies move and the socio-cultural and micro-political implications of this movement has been lacking, as have the multiple and varied perspectives of less committed, recreational or leisure runners. 
Our key concern in this paper, therefore, is to start developing a better understanding of jogging by considering the ways in which the 'brute fact of movement' is pervaded by a range of embodied experiences, social interactions and co-constituted meanings that come together to produce running as a mobile practice. It is important to do this not least because of the extent to which jogging is advocated in a variety of social and political arenas on the basis of the benefits it can bestow. High profile campaigns have developed 'official' narratives of regular exercise being associated with physical and mental fitness, inexpensive and sustainable mobility, and so on (Change4Life 2014; PHE 2013, 2014; run2work 2014). We do not seek in this paper to undermine the central claims of such campaigns - all three of us are to a greater or lesser extent joggers ourselves ${ }^{2}$ - but we do want to uncover aspects of recreational running that we judge require more detailed explication, in the context of encouraging and promoting the advertised benefits of the practice. First are the subtleties in meanings associated with jogging that enable greater insight into people's experiences of 'going for a run'. We highlight positive as well as negative meanings, and seek to illuminate the nuances and implications of apparently less-desirable aspects of jogging. Second, in studying the actual happening of jogging between point $A$ and point $B$ (or, more likely, A!) we explore how along their route recreational runners negotiate the kind of shared spaces that are predominantly the domain of cars and pedestrians. It is, of course, in the interest of both the runner and those being passed by that convivial interactions are achieved between different mobile bodies engaged in different modes of movement.

Against this background, we investigate the movements, meanings and experiences of 19 joggers in Plymouth. We consider the 'brute facts' of movement demonstrated by our participants, but also the meaning and representation of their running and the embodied experiences of their running practices. To begin, however, we place the practice of recreational road-running in context.

\section{Writings about running}

In essence, the brute facts of movement concern the raw material of mobility: who is moving, where are they moving, how fast are they moving, when are they moving, how often they move, how long are they moving for. Sadly, as Winters (1980) has noted, such data are not easy to come by in relation to running. Even nowadays, when the road-runner has become a ubiquitous urban figure (Latham 2013), there is still little information regarding the 'brute facts' of runners' movements. Sport England's Active People Survey has begun to provide some insight into who is running and how often through its monitoring of participation in sport. Road-running is included in the survey under the bracket of 'Athletics', which also 
incorporates the mobile practices of track and field, cross-country running and ultra-marathon running (Sport England 2013). Participation in athletics in England has risen sharply in recent years. Standing at just over two million by $2012 / 13$, it has increased by around 680,000 since 2005/06 (Sport England 2013). Although The Joggers [sic] Manual (quoted in Latham 2013, 1) suggests that "anyone - six to 106 - male or female" can jog, we can identify those who are most likely to undertake the practice. In England, at least, in absolute terms the largest single group of road runners consists of white males between the age of 35 and 44 who have no limiting disability, hold higher income jobs and are not affiliated to formal coaching or a running club (Sport England 2012a).

Until recently, knowledge about where and when people run was extremely scant and anecdotal at best. Notwithstanding a claim in The Joggers Manual that running can take place anywhere, other sources suggest that road-runners generally use city parks, walkways, trails and streets for their practice (Hockey 2006; Latham 2013; Whelan 2012; Winters 1980). A recent Sport England (2012b) survey has now confirmed these assertions, indicating that $80 \%$ of runners frequent the roads, $56 \%$ utilise local parks / off-road areas and only $10 \%$ run on tracks (although club members are five times more likely to visit these). Allen-Collinson and Hockey (2001) show that running is usually temporally organised, with shorter midweek runs and longer weekend runs linked to labour and daylight patterns, and Tulle (2007) and Smith (2002) suggest that such organisation assumes cyclical rhythms across weeks, seasons and years.

Although so far described here in rather abstract terms, we know such movements are imbued with a range of meanings. Over the last few decades, numerous authors have explicated representations of running. Tanio (2012) suggests these fall into three categories: competition, health and those that are experience-orientated. Competitive running is represented as being concerned with how fast bodies can reach their destinations, seeking quicker times and the enhancement of performance (Shipway and Jones 2008; Vettenniemi 2012a). Runners' urge to improve can be a very scientific endeavour, with a 'Taylorisation' involving statistics, records and speeds. Indeed Bale (2004, 2011) suggests that the sweat, slog and physical labour some runners commit to reducing times can function to recast running as a work rather than a leisure activity (Hockey and Allen-Collinson, 2013). Representations of running in relation to health emerge in part from its function as a means of exercise associated with 1960s campaigns to adopt fitter lifestyles (Latham 2013; Shipway and Holloway 2013). Especially resonant with older runners (Dionigi, Horton and Barker 2013; Tulle 2007), the practice of fitness running took hold as a means of counteracting the ill-effects of increasingly sedentary lifestyles. Such things remain important today as 
governments seek to tackle rising obesity levels by promoting healthy living and physical well-being (Shipway and Holloway 2010).

Taking a more bottom-up orientation and often emerging from runners themselves, so-called experience-orientated representations are splendidly varied in character. Jogging has been fashioned as resistance by several authors, who argue that it transgresses the norms of modern achievement sport and contests the dominance of motorised mobility by claiming back the streets (Bale 2003, 2004, 2011; Cidell 2014; Winters 1980). Lorimer (2012) has shown that such taking of space can position road-running as a tool of exploration in that it becomes a vehicle through which to gain place knowledge. As being in place ultimately entails not being somewhere else, some commentators represent road-running as a form of escape, offering a reprieve from the complexities and confusions of everyday life (AllenCollinson and Hockey 2001; Bale 2004; Seagrave 2000; Shipway and Jones 2008). Indeed, the practice of habitual escape has led to suggestions of running constituting a quasi-spiritual endeavour (Spooner 2014). Others have demonstrated running's sociability, in that it may be framed as means of forging and maintaining social relationships (Allen-Collinson 2008; Shipway, Holloway, and Jones 2013).

Yet it would be wrong to say that all representations are positive. Perhaps sitting at odds with 'official' narratives of running as a desirable mobile practice, one view holds running as a form of punishment since it can be related to the compulsory school run (Bale 2008). Such involuntary mobility can leave a legacy of deep-seated resentment that lasts well beyond school years and renders some people unable to grasp why others may entertain the notion of running of their own accord. (Jean Baudrillard [1989] likens it to freely-entered servitude!) Equally, such negativity is by no means straightforwardly directed against engaging in running. It can, in fact, be turned on its head: the difficulty and hardship often associated with running also posits it as a feat, and many runners like to rise to a challenge (Shipway and Jones 2008; Townsend 2012; Vettenniemi 2012a; Whelan 2012). This complex relation between positive and negative meanings is clearly something that any attempt to promote running as a healthy and sustainable practice needs to wrestle with.

Although the mobilities turn has prompted significant engagement in dialogues to do with the body, embodiment and the experience of movement, relatively little work has paid attention to the actual experiences of 'doing' running. Among that which does exist is Lorimer's (2012) phenomenological account of how running can serve as a powerful reminder that we live out our lives as bodies. The body is at the core of a runner's experience, and the experiences of the running body are mostly lived through the senses (Allen-Collinson 2011; Maivorsdotter 
and Quennerstedt 2012). Senses help to mediate between self, society and body and are extremely pertinent to runners as they touch, smell, feel, hear and see their runs (AllenCollinson and Hockey 2011; Hockey 2006, 2013; Hockey and Allen-Collinson 2007, 2013; Lorimer 2012). The senses are essential to accomplishing a run by, among other things, gauging ability, judging proximity, calculating safety, recognising terrain and assessing pace toleration, particularly when running with somebpdy else.

A theme recurring throughout the literature on the running body, again tied up with potentially negative meanings, is that of the body in conflict. Most commonly of interest are tales of conflicts between the mind and the body. Shipway and Jones (2008) write about the frequent and clear conflict between the mind's will to continue and the body's will to stop, a phenomenon intensified by fatigue. The opposite of this is the 'runner's high'. Described by authors as the point when all effort becomes effortless, runners are seduced by their own rhythmicity and a lingering sense of well-being, providing a heightened sensitivity to the present moment (Lorimer 2010, 2012; Tanio 2012; Whelan 2012). It is also possible for these lows and highs to exist very much out of isolation: running can evoke exhilaration, pain, freedom, anxiety, pride, excitement and euphoria, amongst other feelings (Allen-Collinson 2005; Bale 2004; Lorimer 2012; Shipway and Jones 2008; Whelan 2012).

While mind and physical body are obviously central to the running experience, they do not exist in a vacuum. Running is and has always been an interaction between the body and environment (Eichberg 1990; also see Winters 1980). Perhaps one of the most intense of these interactions is that between the runner and topography as s/he moves through and over different slopes and surfaces, becoming a student of terra firma and its implications for the body (Allen-Collinson and Hockey 2011; Hockey and Allen-Collinson 2006; Lorimer 2012). Grass offers a more gentle and elastic surface to cushion joints but can sap energy, while energy loss can be of less concern when running on stiffer roads that enable speed but have implications for joints and tendons. Although the runner may come into contact with many different surfaces, the majority of road-runners in the UK perform their mobility in the predominately-concreted public-spaces of urban areas (see Sport England 2012b).

Moreover, runners are accustomed to running in spaces replete with an obstacle-course of traffic, dogs, pedestrians and other runners, yet there are no natural conventions to regulate the sharing of space or codes of conduct to help avoid possible conflict (Allen-Collinson and Hockey 2007; Hockey and Allen-Collinson 2013). Regular encounters with real and potential obstacles can have significant impact on the rhythm of running, and while many authors agree that the idea of rhythm seems intrinsically important to running, none have investigated 
the concept much beyond identifying the different spatial scales - from bodily to city-wide in which it appears significant (Lorimer 2010; Sanders-Bustle and Oliver 2001; Whelan 2012). Similar topics that in relation to running have received little more than passing or indirect comment include travel-time use and stillness on-the-run, despite both themes commanding significant attention in the broader social sciences (Bissell and Fuller 2011; Jain and Lyons 2008).

Clearly, then, it is evident that a fair amount of headway has been made in uncovering the meanings and experiences of running, mainly in relation to athletic, serious and/or competitive contexts. In the space that remains we wish to explore further some of these meanings and experiences in specific relation to jogging, and its diversity of participants, styles and environments. We explore meanings by connecting into ideas about what use is made of running time and the values associated with participating in recreational running. Understanding the nuances of positive and negative meanings associated with running provides a potentially useful grounding from which more effective means of promoting the practice could be developed. Our focus in terms of experiences is on the ways in which jogging in shared public spaces rarely happens in isolation from non-runners, and so how particular negotiated socialities emerge through and punctuate the rhythms of runners' activities in the shared infrastructures of the city. Again, if there is a desire for increasing participation in jogging, it will be useful to better understand how running bodies fit into the paths and pavements of urban environments, and the varying rights to space between different mobile subjectivities.

\section{Researching running}

Recent research interested in movement and mobile practices has challenged how researchers engage with mobile subjects when they are actually on the move. Some argue that traditional research methods have dealt poorly with the fleeting, the ephemeral, the chaotic, the complex, the sensory, the emotional and the kinaesthetic (Büscher, Urry, and Witchger 2010). Increasing scholarly interest in life-on-the-move has given rise to an array of methods that are themselves 'on-the-move' and as such capable, it is argued, of enabling new forms of inquiry, explanation and engagement (Büscher and Urry 2009; Spinney 2009). This has entailed a significant focus on, for example, various forms of video method, autoethnographic participation, go-alongs and so on. That said, as Merriman $(2014,170)$ has recently noted, "there is a distinct danger of overstating the newness of the research topics, mobile experiences and sensations, and indeed of these mobile methods," when it comes to researching various forms of mobility (see also Shaw and Hesse 2010). In this sense, the 
use of various forms of mobile recording technologies (like video) do not necessarily present 'the answer' in and of themselves when it comes to trying to understand various forms of mobile practice, and do not preclude the useful inclusion of more traditional (if tinkered with) social science methods (Simpson 2014).

With the above in mind, in this research we engaged with the experiences of 19 recreational road-runners. To gain an indication of the physical movements of road-runners, online training diaries were collected from 12 of the 19 participants over a one month period from 1 June 2012 to 30 June 2012. We asked them to map each run they made, using the popular MapMyRun online software (Hirsch et al 2014) to record details of dates, times, durations, speeds, weather, effort and feelings as well as providing a description of the running experience.

From that starting point, the meanings participants attributed to and associated with their recreational road-running, and the experience of running itself, were derived from two forms of participant interviews. Firstly, six of the 19 participants were joined on one of their runs for a 'go-along' interview. These participants were asked to suggest a convenient time and location for a joint run of 30 to 90 minutes, with the route being entirely of their choosing. The run was then completed at 'conversational' pace (an undefined speed that means both runners can hold a conversation without becoming breathless). Dialogue was very looselystructured to allow for the adaptation of topics to changing situations, and for questions to evolve from spontaneous exchanges or encounters on the run. Going the 'extra mile' (Vettenniemi 2012b) like this has been argued to generate richer data as participants are prompted by meanings, connections and memories relating to the surrounding environment and passing events, as well as building deep rapport with the researcher (Anderson 2004; Evans and Jones 2011; Holton and Riley 2014; Jones et al 2008). Indeed, in our experience while at times the topics and nature of discussion in the go-along interviews followed a course that may have been charted by standard interview techniques, running with participations did yield additional insight. Most obviously this arose from the immediacy of reactions and responses to stimuli along the route, but it also became clear during the course of the research that the shared experience of a familiar practice facilitated the quick development of a rapport between researchers and researched. This seemed to encourage very personal, honest, and emotionally charged responses to our questions.

Secondly, eight of the 19 participants undertook mobile-video-ethnography elicitation interviews. This method has been utilised in cycling research (Brown and Spinney 2010; Spinney 2009, 2011; Simpson 2014) and claims are made about its ability to (albeit partially) 
'capture the moment' (Büscher, Urry, and Witchger 2010), to reveal the humdrum and banal aspects of mobile practices, to retain the context and detail of practices and allow for the scrutiny of practices (Simpson 2014). Such an approach also allows participants to relive experiences and allows researchers to talk through the practices, interactions and experiences on the minute scale. In this sense our elicitation interviews complemented the go-alongs since the acts of jogging and being interviewed simultaneously inevitably limit the amount of detail, and indeed the number of events, that can be responded to on any given run. The mobile-video-ethnography interviews were based on unaccompanied runs recorded via a head camera (see Brown, Dilley, and Marshall 2008); the unedited footage was watched separately by both participant and researcher, the latter drawing up a specific interview schedule for each participant. The interviews involved re-watching the video whilst working through the interview schedule.

\section{Meanings of road-running}

In this section we explore ideas of 'escape' and 'absorption' that can emerge from recreational road-running as discussed by our participants, before moving on to consider how such running can be seen as a 'chore' in some distinction to a form of 'punishment'.

\subsection{Running Away? Running as Escape}

Allen-Collinson and Hockey (2001) have argued that runners regularly exploit running for the respite it can provide from the complexities and commotions of life. This meaning is a representation of running that was recognised among our participants, with some able to shed great light onto the ways running can be represented in such a manner. This 'use' of running/travel time as escape holds many connotations and implies 'getting away' in the sense of respite from a range of different troubles.

One way in which road-running does this is by granting the freedom to move - movement that can serve to counteract or even neutralise feelings of confinement or claustrophobia associated with particular woes. (Interestingly, such feelings can be expressed in the context of various spatial scales, from that of a room all the way up to the city itself.) As one participant explained:

'The original reason I first started taking up running again in Plymouth was I felt locked inside those tiny little rooms in university halls ... and I suffered depression the winter before last and I thought I'll go out, get healthy, get some fresh air and it all started from there ... It's a complete escape, from being trapped inside the house or trapped inside the city centre with no means of getting out. I used to love Central Park because it is so quiet 
and you kind of escape from the noise and the city because I am a country person that moved into the city and never realised how noisy and non-stop it is. It doesn't stop at night or ever but at Central Park, it is quiet.' (Go-Along)

More than just literally getting out, then, running can give the chance to go somewhere different and experience something quite removed from ones usual day-to-day encounters. This sense of escaping to something different, to someplace more desirable, was also discussed by another participant when in conversation about his preference for running in more 'natural' places:

'I think it's just not having the cars, no other distractions and then occasionally you look up and there will a bird of prey on the way in or something going on. But it's just the clean air I think, so occasionally I will get across on the ferry and run around the coast that way; Oreston [a suburb of the city next to the River Plym] is always quite a nice one - it's really hilly.' (Go-Along)

For at least one of our joggers - and we suspect rather more than that - the 'someplace else' is a very deliberate locational choice. Such places, or rather routes through places, enable us to revisit memories of past events that possess specific connotations of comfort and familiarity, quite at odds with what as been left behind.

Yet moving between places does not only involve the passing through and exchanging of spaces. Making such movements requires time, and this can also be used as a means of bounding problems, in the sense of securing troubles in one locale. The duration and distance of the run can thus be used to put time and space between runners and their troubles. In one particularly vivid exemplification of this point, a participant explained:

'I work as a social worker and have done for about 15 years and l've always dealt with confrontation and I've dealt with challenges... I try and run home from work and... my run home can be my de-stress, well not de-stress because I don't get stressed but I think clearing out my mess before I get home... I'm very boundary setting, my home is my space so I don't like to bring work into my house or I don't like to bring the worries or the anxieties or the confrontation into my house so I will run home... that is my escapism.' (Video-Ethnography)

These sentiments also chime with Jain and Lyons' (2008) discussion of the role of travel in facilitating transition - adjusting mind frames, shedding burdens and experiencing distance - 
between work and home. Mobility in this sense can be a highly 'productive' experience, both in and of itself (precisely because it allows certain things to be accomplished while on the move) and in terms of its potentially positive impact on future activities (such as a better experience once home is reached).

It goes without saying that the time that running gifts those who choose to undertake it can be very personal in nature. Running does not just enable one to escape to or from a particular place(s), but also to escape into oneself. This became evident in one of our goalong interviews where the runner started to reflect on the characteristics of his immediate surroundings as he ran through them:

'It's so de-stressing, l've got proper time to think and I never get that anywhere else. Normally because I live in a flat with people who insist the TV's on all the time. Yeah. I like to have that time to think, you know, that you just can't get elsewhere and I think, as I say, that comes back to the noise as well, noise of the cars and everything. You just don't get time to think unless you go out where you can block it out of your mind.' (Go-Along)

Thinking, and more specifically having the time to think while on the move, can be a great gift to the runner; in particular, the combination of being somewhere else and having time to oneself can be especially positive:

I go out and start thinking. Very often, something rational that I didn't think of throughout the whole day, suddenly comes to my mind... This can be solved so easily if I just took five seconds out and stopped worrying. I can problem-solve while running' (Go-Along).

I make decisions when I'm running because it is my time and I don't have the distractions around. Sometimes that really helps. If I am really struggling with something I'll just think, 'I need to go for a run, let's think about this.' Because I am away from home, away from work or whatever, and l'll just go' (Video-Ethnography).

Finally in terms of constructing running as an escape, the very act of movement can be key. Here we refer not just to moving to get elsewhere or to the time afforded / taken by such movement, but the physical and bodily act of moving. Farquhar et al (2011) suggest that it is 'absorbedness in action' that allows the mind to solve problems, or the quickening of the pulse that can reveal different perspectives on life (see also Lorimer 2010). But what exactly is it about moving and the rhythmic action of running that helps a runner to escape? In a very 
personal account, one participant suggested that such absorbedness in action had the ability to overwhelm thoughts and emotions, instead focusing, at least for a time, the body on consuming mobility:

'I remember very vividly when my granddad passed away, that I got that phone call and my housemates went 'you all right?' - 'yeah, going for a run'. I just ran and ran and I ran harder and harder until I kind of shut out everything, and then just eased up and let little bits in at a time when I was taking it in as I ran away. So not trying to forget it completely but it's just trying to use that rhythm to control each thought till I came back and went "he was 85 , he had a really good life." (Go-Along)

Here our participant shows how running, in a sense, acted to clear his mind and, once this had been achieved, enabled emotions to return in small, manageable chunks. In effect, our participant escaped his worries by engulfing himself in motion and then confronting his feelings gradually when he felt able to begin the process of constructing a more agreeable perspective.

\subsection{Running as chore}

Contrasting with these views on escape, running was also constructed as a chore by participants in our study. Although related to the theme of punishment mentioned earlier (Bale 2008), to our respondents the notion of a chore seems to incorporate some sense of choice and value. Running may well be something that from time to time one is reluctant to undertake, but one nevertheless does so for the benefits it is perceived to bring. In response to the basic question, 'why do you do running?' it was not uncommon for participants to say something along the lines of, 'Oh, God, I ask myself that all of the time!' or 'Good question.' An air of (resigned?) sarcasm was detectable in these responses, but nevertheless we interpret three main ways in which running was represented as a chore: it is painful, it is inconvenient and at least in the sense of viewing any one run in the context of many, it is pointless.

Constructing running as a chore based on the toil expended and pain it can produce is an easy representation to fathom. Indeed, as one participant summed up with particular frankness, 'It just tires you out; it's not that fun being knackered is it?' (Video-Ethnography). Occasionally, however, running was described as becoming a chore long before the foot is even in the trainer. To those of our respondents who made this point - essentially that just thinking about running can cause mental fatigue well in advance of actually doing it - the principal issue appears to be the amount of time it requires. This is, of course, the very same 
time that others view as important for escapism, but someone whose time is in short supply might find the prospect of diarising a run a source of some stress. In short, it was explained to us that for such people the time in which running is to occur must synchronise with the rest of their life's rhythms. A clash leading to a perturbation of these rhythms - picking up the children from school, meeting a deadline at work, going out for a drink with friends - can all too quickly cast running in a new and distinctly less favourable light. This remains the case even when the competing activity in question impacts upon no-one other than the joggers themselves. It is not only the time the run takes but also its implications for their broader quotidian activities:

'It's all to do with when I am washing my hair... because if I'd just been in the shower, I'd spent two hours drying and straightening my hair - I don't wanna go on a run straight away and have to do it again as soon as I come back. Just for ten minutes' running... So I wouldn't do it then. I would wait to just before I need to go in the shower and then I'd do it.' (Go-Along)

The final construction of road-running as a chore develops from the idea of pointlessness. We referred at the start of the paper to pointlessness in relation to the 'traditional' sense of movement from $A$ to $B$; many, perhaps the majority, of runs go simply from Point $A$ to Point A. Some of our participants sought to instill a purpose in their activities beyond that of escapism or getting fit by building a run into other day-to-day tasks. One participant explained how, when running by himself, he will often plan to ascribe purpose to his run as a means from getting from $A$ to $B$ and of accessing benefits that $B$ can give him. It is this newly ascribed meaning to the run that counteracts any sense of chore and ultimately encourages it to be undertaken:

'When I run on my own I usually try and incorporate it with going to the shop. I'll run to Asda and get some chocolate... it's sort of a reward and it gives the run an aim.' (VideoEthnography)

Of course, aligning running with everyday activities such as picking up small grocery items, or visiting a friend, or going to work, also allows joggers to address issues of limited availability of time and flags an interesting way in which such recreational running could be aligned with sustainable and active transport agendas (see Cook 2014; run2work 2014). 
One intriguing theme that emerged in relation to pointlessness, mentioned particularly by regular joggers, was that it can be difficult for them to discern the benefits they might derive from any one specific run in the context of a multitude of habitualised outings. Perhaps particular well-worn routes become too tedious to contemplate further repetition; perhaps the prospect of going out alone is demotivating; perhaps it is the weather that makes the idea of staying in by the fire more appealing. One might well wonder at this juncture why these people continue to force themselves out of the house to undertake such a chore. In essence it is because they, like everyone else, ascribe not one but a number of meanings to jogging. Some of these are positive, some are negative; some complement each other and some compete with each other. Thus while any one run might seem pointless at the time at which it is being contemplated, a deeper understanding of the long-term place of running in these respondents' lives helped turn a chore into an activity still worth undertaking. The ability to associate multiple meanings to one practice - one that may immediately appear tiresome but which ultimately will help achieve / retain fitness or precipitate weight loss - bestows, albeit grudgingly in some circumstances, purpose upon that inconvenient and pointless run.

\section{Experiencing running: negotiating space}

The many ways in which running can be experienced, the ways in which lines on a map can be brought to life and from which some of the representations discussed above are brought to fruition, are diverse. Here, though, we focus in specific relation to jogging on a single theme that was discussed by all of our participants, and which to us as geographers (and as joggers) was immediately the most striking - that of negotiating shared space. The fact that all of our respondents alighted upon this particularly quotidian issue was instructive. A range of scholars (for example, see Pooley, Turnbull, and Adams 2005) rightly make the point that it is all too easy to over-emphasise the rare and dramatic experiences of mobile (and other) practices at the expense of the 'mundane' or everyday. In relation to mobile practices, it is often the humdrum, ordinary and in many cases easily forgotten experiences that are the most important - or at the very least, the most commonplace - when considering how such practices are actually accomplished and embodied (Simpson 2014). This banal day-to-day happening of running is actually very significant in that it often entails a wide range of social interaction with strangers in a range of urban spaces. At the micro-political scale, the convivial happening of such interaction is a key issue for increased participation in this practice. Correspondingly, we focus in this section on how joggers manage to negotiate shared space whilst on the move. In particular, we are interested in the practice of passing pedestrians; how movement, people, things and place interact to establish a kind of dynamic order. The outcome of these passing encounters similarly provides insights into the varied 
rights to space and mobile hierarchies that exist on the street (see Brown 2012; Jensen 2013).

Hockey and Allen-Collinson (2013) have noted that competitive road-runners are accustomed to running in public spaces while training and so managing the variety of challenges, obstacles and encounters - indeed, running the gauntlet - that momentary meetings with pedestrians routinely generate in shared space. This is also true for joggers. As one participant put it, the intensity of such interactions are commonplace to the extent that they become an integral experience of road-running:

'I don't really like it when it comes to running on the pavements... and sharing it with other people because you have to get out of their way and they have to get out of your way and they don't see you and crossing the road rather too frequently. It is quite dangerous because I think drivers expect runners to get out the way, not to be there.' (VideoEthnography)

We also see in this statement the idea that, although commonplace and familiar, there are no rules, no conventions, and no codes of conduct for negotiating such encounters. Hockey and Allen-Collinson $(2007,2013)$ suggest that no consensus exists regarding how best to regulate the sharing of space by differently mobile subjects. Examining this further, our discussion provides insights into how and why shared space is negotiated in the ways that it is.

\subsection{Mobile politics and order on the street}

Mobile social order often arises out of ongoing competition for and over spaces, and a frequent outcome of such continual giving, taking, receiving, and conceding of space is conflict - endless numbers of battles over space and mobility (Binnie et al 2007). Of course, most of these battles are resolved in split-second decisions taken to avoid collision and thus escalation into a higher level of potentially troublesome conflict (as demonstrated by the reprimanding of a jogger who failed to successfully avoid Prime Minister David Cameron on the streets of Leeds in October 2014 [BBC, 2014]). It is for this very reason that further investigation of collision-avoidance strategies is of significance. Hockey and Allen-Collinson (2013) contend that runners are deemed the ones responsible for avoiding pedestrians because of notions surrounding the 'normal' use of a pavement. While it is not possible to provide a full taxonomy of how joggers might come to be constructed as liminal bodies in such spaces, it became clear that their higher speed (and momentum) was a central component in the formation of such a classification. While the joggers we interviewed here 
suggested a more complex situation, we can determine three predominant viewpoints on how joggers should pass pedestrians in shared spaces. These placed varying degrees of emphasis on joggers, on pedestrians and on the need for joint management of arising situations.

Joggers believing that responsibility should rest with themselves tended to agree with Hockey and Allen-Collinson (2013). For these people, the idea that they are a minority with regard to how they use the streets carries with it a responsibility to ensure passing encounters are handled successfully. It is just more practical and convenient for joggers, as the minority, to make the effort to avoid pedestrians rather than expect the majority to avoid them:

'No, I see it as my responsibility. I think everybody else is trying to use the environment in a relaxing way and there is me trying to use it in a more, probably, productive but personal way. So I think it is my job to not interrupt their free time in the way that because... I can do that but I wouldn't expect a hundred people to move out of their way to avoid me and my free time... I think that would be selfish because clearly there aren't as many runners as there are dog walkers for example... We are probably inconveniencing their space.' (Go-Along)

Here pavements (and to an extent streets more broadly - see Jacobs 1961; Shaw and Docherty 2014b) are understood as predominantly a space for walking and the general rhythms and tempos that go with that. By contrast, those movements made by different modes stray from this 'norm' and so can be seen as out of place. Perhaps running could be characterised alongside skateboarding in this respect (Borden 2001). Yet although some of our respondents were happy to assume responsibility for avoiding collisions with others in shared spaces, none were happy to go as far as to conceive of themselves as engaging in a deviant act. As one stated:

'I think these places were built for it! I think these days, perhaps not originally, obviously this is a manor house park, but at some point somebody went, 'we'll turn that into a public park' and they must have known that people that want to go for a run are gonna use that. And if they didn't, they weren't thinking.' (Go-Along)

The participant here was clearly referring to pathways in parkland rather than pavements along a street, yet his point still stands: running may not have been the originally preferred or anticipated activity, but its now-frequent presence within the developed world (Latham 2013) 
should be enough to counter inferences of deviance. These days the jogger is, or at least should be, an expected mobile subject.

The principal cause of disagreement among our respondents as to whether they or pedestrians should hold responsibility for collision avoidance seems to be speed. Those who advocate joggers' obligations claim that the speed at which they are moving, which is probably greater than might be anticipated by many on the streets, makes it incumbent on them to bear the responsibility: 'I think I would take responsibility because I'm the one moving faster' (Go-Along interview); 'It is my responsibility to make sure we don't hit each other because I'm going faster' (Video-Ethnography). Yet others use the identical argument that joggers are moving more quickly than pedestrians - to impose this responsibility upon pedestrians. As one noted: 'Because they're walking and I'm running, they can get out of my way' (Video-Ethnography). Another remarked that 'I'm going at the fastest pace, just like if you were cycling you'd expect them to move'3 (Go-Along interview). Perhaps we shouldn't be surprised that differences in speed can form the basis of two antithetical arguments; on the one hand, joggers learn to be more attuned to the chances of a collision and thus are more likely to be vigilant against such occurrences. On the other, pedestrians' relative slowness gifts them an advantage in agility, enabling them to stop more quickly or more hastily change direction than joggers in the event that they are surprised by a potential collision.

Most participants in the study happened to be of a more diplomatic viewpoint, however, advancing the view that the task is a shared one: both parties have equal claim to space and as such both joggers and pedestrians should be involved in negotiating their fleeting but important encounters. In a Go-Along interview, one participant commented simply that, 'I always think it is our responsibility as much as anyone else's.' Other remarks were that, 'It [the responsibility] would be both of ours" (Video-Ethnography) and 'I think it's a joint effort' (Video-Ethnography). Intriguingly none of the respondents offered any lengthier analysis of the matter.

\subsection{Passing pedestrians}

The existence of these differing views about who should assume responsibility for avoiding conflict when pedestrians are passed rather begs the question of how passing-by is actually accomplished. Such an accomplishment is born out of the negotiation of many micromovements, acting as micro-political statements that accept, reject, permit or inhibit ones rights to movement and inclusion in space (Till 2012). Although a number of approaches were demonstrated by our participants, they were all in some way or another related to three in particular: choosing a side, stepping down and slaloming. The tactic of choosing a side is 
predicated on the assumption that both joggers and pedestrians share some responsibility for preventing a collision from occurring and thus are equals in the mobility hierarchy. Joggers use bodily movements to signify their intention but rely on pedestrians responding appropriately (or at least as the approaching jogger expects them to). As one participant explained: 'My strategy is I pick a side I am going on first... I choose a side of the pavement first so they can see that I am on that side of the pavement' (Video-Ethnography). Another more stridently reported that they used overt bodily gestures to show their planned movements: 'I kind of like duck to one side as an indication saying 'I'm leaving you space to get past this side - kind of take the hint or I will run into you!" (Video-Ethnography). Although the action of physically moving is a strong indication of the way a jogger would like to negotiate the situation, it is generally at its most effective in relatively straightforward scenarios such as that captured in Figure 6, where the direction of the pedestrian being passed is evident and does not run in parallel to the direction of the jogger.

\section{FIGURE 6 HERE}

More complex situations - such as when space is narrow, there are large groups of pedestrians, or the jogger is approaching from behind - often rely not only on the jogger taking more (and often complete) responsibility for collision avoidance, but also on using the body far more actively than to indicate intent and follow a pre-determined course. We introduce here two further tactics used by our participants - stepping down and slaloming. Stepping down refers to when a jogger steps off the pavement, choosing to run in the separated space of the road to avoid conflict with pedestrians. This can be seen in Figure 7 where the jogger, in approaching the dog walker, takes a very wide berth, including moving onto the road (image c), despite there appearing to be enough space on the pavement. The unpredictable nature of the dog and the risk of tripping over it or becoming entangled with its lead resulted in this precaution. We do have to acknowledge from the outset that to some, this notion is unfathomable given the risks involved in entering the carriageway. Yet to others the danger from potentially 'erratic' or perhaps encumbered space-sharers is greater than that from cars, whose movements somehow 'flow' more reliably or who might have more room for manoeuvre. This is significant (and was, it has to be said, rather surprising until we actually sat down and thought about our own practice) and so requires some explanation. One respondent pointed out that if the momentary meeting of jogger and pedestrian occurs in limited space, inevitably something must give:

'I would much rather be the person who got in the road than move somebody else into the road because I would feel like that would be my responsibility. I mean they are not going 
to die but say if something happened in that second, that would be my fault' (Go-Along Interview).

Others came from a slightly different perspective, revealing a sense of duty towards fellow space-sharers in the sense of not wishing to endanger them as a result of being on a run:

'Yesterday there was a guy walking his dog up towards Plymstock and he went to go in the road and I went 'no no, I'll go in the road, mate' and I think he appreciated that. But I appreciated his gesture but he had two little dogs on a lead and it's easier for me to stay narrowly in the road than it is for two dogs' (Go-Along Interview).

\section{FIGURE 7 HERE}

The final tactic is the slalom. Again, this requires joggers to take responsibility for creating their own route through a shared space. It involves the weaving of the body around and past other space-sharers (and indeed space-sharing objects), and occasionally is forced upon the jogger as he or she has to adjust quickly to quite unexpected movements made by others. As one participant noted in explaining the sequence of events in Figure 8:

Researcher: 'So here you are just about to overtake some people but you do so in quite a strange fashion. You seem to be going to the left and then all of a sudden change your mind?'

Participant: 'Yeah, because that guy, he didn't seem to be too aware of me and started to move further to the left, so I thought if he is moving further across, I don't want him to just step into the path I was going so I thought I would just take that out of the equation completely' (Video- Ethnography).

Although it is the most difficult and potentially disruptive means of passing-by, there are occasions when it may be a preferred option. In such situations it is useful at least to have some opportunity to survey a situation before actually deciding what to do. One respondent chose a slalom because, 'I saw it from a while off. I just squeezed through. It would take less time to squeeze through then go around to the left and I won't have to go back on myself' (Video-Ethnography). For another:

'Well I knew what pace I was going at and what pace they were going at and I worked out that instead of going in the road and around the car, that if I just waited for half a second I could just squeeze through a gap between them' (Video-Ethnography). 
It is clear from these passages that decisions about whether to choose a side, step down or slalom have to be made momentarily. This does not necessarily mean they are random or that they are straightforwardly habitual or mindless; it is rather that our participants had become quite adept at making quick and calculated judgements to inform them about which spatial tactic would be the best, most appropriate and plausible in any given encounter. Such an attunement, interestingly, brings to light a difference between participants' views on how encounters should be negotiated, and how they actually happen. While most of our participants suggested some shared responsibility with pedestrians, all too often the burden of negotiating such encounters falls solely upon the joggers.

\section{FIGURE 8 HERE}

\section{Conclusion}

In this paper we have sought to provide an account of some of the movements, meanings and experiences (Cresswell 2006) that together help produce the practice of jogging. Jogging is evidently a popular pursuit, and although the statistics are somewhat difficult to disaggregate, it would seem that participation has increased in recent years (Sport England 2013). High profile campaigns have consistently associated regular exercise with physical and mental fitness, and we set out to uncover aspects of jogging that require more detailed investigation if its advertised benefits are to be effectively encouraged and promoted. In doing so, we engaged with the experiences of joggers in Plymouth and discussed two key aspects of their practice. The first of these relates to the meaning associated with joggers' movements. While potentially a 'pointless' form of mobility in terms of the relationship between origin and departure (Cidell 2014), these movements can be seen as an escape, especially within the context of joggers' day-to-day activities. Further, drawing upon other authors' discussions of running representing some kind of punishment, we have provided the connected but contrasting picture of jogging being a form of 'chore' that includes both negative and positive meanings, associations and outcomes. Indeed, we found that the meanings tied up with jogging are more varied, kaleidoscopic and co-existing than those to be found within the existing literature on running. It seems clear that meanings tied up with competition and health only give a very partial picture of the practice - there are many more to uncover. By working with a number of different joggers we have also started to complicate the at times heavily romanticised or hyperbolically negative views of running that appear in various, often autobiographical, accounts of running practices. 
Secondly, we examined in detail the experience of jogging in the shared spaces of the city. A key feature of jogging is that in contrast with other forms of more organised and/or competitive running, it rarely happens in isolation from non-joggers. Sharing pavements and paths means that various tactics and skills need to be employed in maintaining harmonious social relations between joggers and other inhabitants of the city. Here we have shown some of the perceptions amongst joggers about whose responsibility it is to 'get out of the way', and how specific encounters with non-joggers can be negotiated in practice. This said, we recognise there is a danger, in focusing on the micro-scale geographies of passing by, of reifying the encounter itself (indeed, this is arguably a characteristic of encounter research more generally). We should be clear that the encounters discussed in this paper were embedded in a broader context of personal and societal histories and geographies. The runs were undertaken by particular individuals and took place in one specific city in one country, and this has implications for the ways in which specific encounters were negotiated. There are likely to be plural running cultures and norms between countries (or cities), as there are with other mobile practices like cycling, driving and using public transport (see Shaw and Docherty 2014b). Just because our participants did not explicitly discuss such matters during the course of our research, does not mean that circumstantial influences were not playing some part in their approach and views towards jogging.

While we suggest that our fine-grained approach to exploring jogging moves beyond existing understandings of the practice, there are numerous potential avenues for further work. Perhaps the most obvious thing to say is that in a paper of this length we did not have space to comment on other issues arising from the literature on serious / competitive running and how they relate to and can be informed by a focus on the movements, meanings and experiences of jogging. And in a similar vein to how the 'passing by' encounters we describe emerge from particular circumstances, each run is a dynamic and unfolding event that contains the potential for differing trajectories of movement and encounter to emerge. There is thus scope for research to be undertaken in a variety of different settings, at different times and at different scales. Although they did not arise during the course of our research, there must surely be questions of how issues such as gender or confidence impact upon joggers' choices of timing and routes taken in an effort to avoid particular times / spaces of fear as they perceive or encounter them. Still another consideration is the way in which non-runners encounter joggers in the shared spaces of the city. In part this is because the inclusion of pedestrians' (and others') voices in discussions of jogging has the potential to add significantly to the analysis, but it is also true that joggers are themselves pedestrians, probably more often then they are joggers, and quite possibly along at least portions of the routes they regularly run. An often-overlooked aspect of mobilities research is that we are all 
multi-mobile subjects (indeed, this is quite common in transport research as well) and a large-scale shift away from a single-mode focus towards something genuinely holistic in mobility terms would be invigorating indeed.

At the broadest level, we know that regular exercise has social (e.g. keeping you fit), environmental (e.g. as a sustainable form of mobility) and economic (e.g. as a means of cutting congestion or reducing the long term burden on the health service) benefits. At least in these contexts, it would seem that the further promotion of exercise is a desirable aim and as such our findings are of interest beyond the realm of mobilities scholarship alone. Policy makers wishing to promote jogging could draw upon a greater appreciation of the ways people experience jogging and the environments through which they move. One example might be the better design of promotional material encouraging joggers to explore and engage with a whole range of different routes - in Plymouth, this has already been done for walkers (Plymouth City Council 2012; Sidaway 2009) - including, perhaps, dedicated pedestrianised spaces. A second example relates to the ways in which pedestrian infrastructure can be designed with a more sophisticated awareness of the needs of all of those who use it, not just those who walk (Middleton 2009). Existing shared-streets initiatives, for example Exhibition Road in London, tend to focus on the interaction between walkers and vehicles rather than between differently mobile pedestrians themselves.

Ultimately, in doing all of this, we should not assume that jogging presents a homogeneous and self-evident means of getting from $A$ to $B$. Rather, jogging is a means of moving through spaces - but, as we have seen, most particularly places - that is inherently heterogeneous in character, both in the sense of the meanings derived by the individual participant and the almost inevitable interactions with others. 


\section{Notes}

${ }^{1}$ We use the term 'jogging' here to distinguish the form of running of interest in this paper from that of the more serious or competitive running of interest to other authors. We pass no judgement on the ability or seriousness of our participants with regard to their running.

2 It is fair to say we each have varied experience of running and jogging. One of us is a faded club runner who has raced competitively at county level. He still jogs regularly today, enjoying more of the experiential benefits of running whilst dreaming of days (and speeds) gone by. Another previously jogged about three times a week to maintain some level of fitness and to counteract the sedentary nature of the academic working day (and his enthusiastic Friday evening drinking). This has largely been interrupted by a niggling hamstring injury. The other has a difficult relationship with running, doing so less often than he probably should and only in good weather.

${ }^{3}$ We do not intend to open this can of worms. For some discussion on how cyclists view such things, and indeed how cyclists' behaviour is viewed by others: see Aldred 2013; Aldred and Jungnickel 2012; Daley and Rissel 2011. 


\section{Acknowledgements}

Thanks to Tim Absalom for drawing the diagrams, and to Tim Schwanen and audiences in Tampa, London and Sheffield, for their very insightful comments on earlier versions of this paper. We are also grateful to the two anonymous referees whose critical reading of a previous version has significantly refined our thinking. Finally, special thanks to the joggers themselves for sharing their experiences and making the paper possible in the first place. 


\section{References}

Adey, P. 2004. "Secured and Sorted Mobilities: Examples from the Airport." Surveillance \& Society 1(4): 500-519.

Aldred, R. 2013. "Incompetent or Too Competent? Negotiating Everyday Cycling Identities in a Motor Dominated Society." Mobilities 8(2): 252-271.

Aldred, R., and K. Jungnickel. 2012. "Constructing Mobile Places between 'Leisure' and 'Transport': A Case Study of Two Group Cycle Rides.” Sociology 46(3): 523-539.

Allen-Collinson, J. 2003. "Running Into Injury Time: Distance Running and Temporality." Sociology of Sports Journal 20(4): 331-350.

Allen-Collinson, J. 2005. "Emotions, Interaction and the Injured Sporting Body." International Review for the Sociology of Sport 40(2): 221-240.

Allen-Collinson, J. 2008. "Running the Routes Together Corunning and Knowledge in Action." Journal of Contemporary Ethnography 37(1): 38-61.

Allen-Collinson, J. 2010. "Running embodiment, power and vulnerability: Notes towards a feminist phenomenology of female running." In Women and Exercise: The Body, Health and Consumerism, edited by E. Kennedy, and P. Markula, 280-298. Abingdon: Routledge.

Allen-Collinson, J. 2011. "Feminist Phenomenology and the Woman in the Running Body." Sport, Ethics and Philosophy 5(3): 297-313.

Allen-Collinson, J., and J. Hockey. 2001. "Runners' tales: autoethnography, injury and narrative." Auto/Biography IX(1-2): 95-106.

Allen-Collinson, J., and J. Hockey. 2007. "Public Space and Running Together: Some Ethnomethodological Considerations." In Academic Renewal: Innovation in Leisure and Tourism Theories and Methods, edited by F. Jordan, L. Kilgour, and N. Morgan, 3-24. London: Routledge.

Allen-Collinson, J., and J. Hockey. 2011. "Feeling the way: Notes toward a haptic phenomenology of distance running and scuba diving." International Review for the Sociology of Sport 46(3): 330-345.

Anderson, J. 2004. "Talking whilst walking: a geographical archaeology of knowledge." Area 36(3): $254-261$.

Bale, J. 1994. Landscapes of Modern Sport. Leicester: Leicester University Press.

Bale, J. 2000. "Sport as Power: Running as Resistance." In Entanglements of Power: Geographies of Domination and Resistance, edited by J.S. Sharpe, P. Routledge, C. Philo, and R. Paddison, 148-163. London: Routledge.

Bale, J. 2003. Sports Geography. London: Routledge.

Bale, J. 2004. Running Cultures: Racing in Time and Space. London: Routledge.

Bale, J. 2008. Anti-Sport Sentiments in Literature: Batting for the Opposition. Abingdon: Routledge. 
Bale, J. 2011. "Running: Running as Working." In Geographies of Mobilities: Practices, Spaces, Subjects, edited by T. Cresswell, and P. Merriman, 35-50. Farnham: Ashgate.

Bale, J. and J. Sang. 1996. Kenyan Running: Movement Culture, Geography and Global Change. London: Frank Cass.

Baudrillard, J. 1989. America. London: Verso.

BBC News. 2014. “Jogger in PM security alert had 'no idea' what happened." BBC News. Accessed 03 November 2014. http://www.bbc.co.uk/news/uk-politics-29784493

Binnie, J., T. Edensor, J. Holloway, S. Millington, and C. Young. 2007. "Mundane mobilities, banal travels." Social \& Cultural Geography 8(2): 165-174.

Bissell, D. 2009. "Conceptualising differently-mobile passengers: geographies of everyday encumbrance in the railway station." Social \& Cultural Geography 10(2): 173-195.

Bissell, D. 2013. "Pointless Mobilities: Rethinking Proximity Through the Loops of Neighbourhood." Mobilities 8(3): 349-367.

Bissell, D., and G. Fuller, eds. 2011. Stillness in a mobile world. Abingdon: Routledge.

Blacksell, M. 2005. "A walk on the South West Coast Path: a view from the Other side." Transactions of the Institute of British Geographers 30(4): 518 - 520.

Borden, I. 2001. Skateboarding, Space and the City: Architecture and the Body. Oxford: Berg.

Brown, K.M. 2012. "Sharing public space across difference: attunement and the contested burdens of choreographing encounter." Social and Cultural Geography 13(7): 801820.

Brown, K.M., R. Dilley, and K. Marshall. 2008. "Using a Head-Mounted Video Camera to Understand Social Worlds and Experiences." Sociological Research Online 13(6): Article 1.

Brown, K.M. and J. Spinney. 2010. "Catching a Glimpse: the Value of Video in Evoking, Understanding and Representing the Practice of Cycling." In Mobile Methodologies, edited by B. Fincham, M. McGuinness, L. Murray, 130-151. Basingstoke: Palgrave MacMillan.

Büscher, M., and J. Urry. 2009. "Mobile Methods and the Empirical." European Journal of Social Theory 12(1): 99-116.

Büscher, M., J. Urry, and K. Witchger. 2010. "Introduction Mobile Methods." In Mobile Methods, edited by M. Büscher, J. Urry, and K. Witchger, 1-19. Abingdon: Routledge.

Cao, X., P.L. Mokhtarian, and S.L. Handy. 2009. "No Particular Place to Go: An Empirical Analysis of Travel for the Sake of Travel." Environment and Behavior 41(2): 233-257.

Change4Life. 2014. "Active travel - get going while you're on the move!". Change4Life. Accessed 03 November 2014. http://www.nhs.uk/change4life/pages/active-travel-ideas.aspx

Cidell, J. 2014. "Running road races as transgressive event mobilities." Social \& Cultural Geography 15(5): 571-583. 
Cook, S. 2014. "Running as transport: a geographical provocation." Master's diss., Royal Holloway, University of London

Cresswell, T. 2001a. "Mobilities - An Introduction." New Formations 43: 9-10.

Cresswell, T. 2001b. "The Production of Mobilities." New Formations 43: 11-25.

Cresswell, T. 2006. On the Move: Mobility in the Modern Western World. London: Routledge.

Daley, M., and C. Rissel. 2011. "Perspectives and images of cycling as a barrier or facilitator of cycling." Transport Policy 18(1): 211-216.

Dionigi, R.A., S. Horton, and J. Baker. 2013. "Negotiations of the ageing process: older adults' stories of sports participation" Sport, Education and Society 18(3), $370-387$.

Eichberg, H. 1990. "Race-track and labyrinth: The space of physical culture in Berlin." Journal of Sport History 17(2): 245-260.

Evans, J. and P. Jones. 2011. "The walking interview: Methodology, mobility and place" Applied Geography 31(2): 849-858.

Farquhar, A., J. Connarty, S. Gage, C. Cooper, S. Hobson, P. Dorward, and H. Lorimer. 2011. "Why we Run." Speed of Light 2012. Accessed 26 January 2013.

http://speedoflight2012.org.uk/downloads/Investigations\%20Panel.pdf

Hirsch, J.A., P. James, J.R.H. Robinson, K.M. Eastman, K.D. Conley, K.R. Evenson, and F. Laden. 2014. "Using MapMyFitness to Place Physical Activity into Neighborhood Context." Frontiers in Public Health 2(19): 1-9.

Hockey, J. 2004. "Knowing the Route: Distance Runners' Mundane Knowledge." Sociology of Sport Online 7(1): 1-10.

Hockey, J. 2006. "Sensing the Run: The Senses and Distance Running." The Senses and Society 1(2): 183-201.

Hockey, J. 2013. "Knowing the 'Going': the sensory evaluation of distance running." Qualitative Research in Sport, Exercise and Health 5(1): 127-141.

Hockey, J., and J. Allen-Collinson. 2006. "Seeing the way: visual sociology and the distance runner's perspective." Visual Studies 21(1): 70-81.

Hockey, J., and J. Allen-Collinson. 2007. "Grasping the Phenomenology of Sporting Bodies." International Review for the Sociology of Sport 42(2): 115-131.

Hockey, J., and J. Allen-Collinson. 2013. "Distance running as play/work: Training-together as a joint accomplishment." In Ethnomethodology at Play, edited by P. Tolmie, and M. Rouncefield, 211-235. Farnham: Ashgate.

Holton, M., and M. Riley. 2014. "Talking on the move: place-based interviewing with undergraduate students." Area 46(1): 59-65.

Jacobs, J. 1961. The Death and Life of Great American Cities. New York: Random House. 
Jain, J. 2009. "The making of mundane bus journeys." In The cultures of alternative mobilities: routes less travelled, edited by P. Vannini, 91-107. Aldershot: Ashgate.

Jain, J. 2011. "The classy coach commute." Journal of Transport Geography 19(5): 1017 1022.

Jain, J., and G. Lyons. 2008. "The gift of travel time." Journal of Transport Geography 16(1): $81-89$.

Jensen, O.B. 2013 Staging Mobilities. Abingdon: Routledge.

Jones, P., G. Bunce, J. Evans, H. Gibbs, and J. Ricketts Hein. 2008. "Exploring Space and Place with Walking Interviews” Journal of Research Practice, 4(2): Article D2.

Latham, A. 2013. "The history of a habit: jogging as a palliative to sedentariness in 1960s America." Cultural Geographies. Accessed 18 February 2014. http://cgj.sagepub.com/content/early/2013/07/22/1474474013491927.full.pdf+html

Laurier, E. 2004. "Doing Office Work on the Motorway." Theory Culture Society 21(4-5): 261277.

Lorimer, H. 2010. "Forces of Nature, Forms of Life: Calibrating Ethology and

Phenomenology." In Taking-Place: Non-Representational Theories and Geography, edited by B. Anderson, and P. Harrison, 55-78. Farnham: Ashgate.

Lorimer, H. 2012. “Surfaces and Slopes.” Performance Research 17(2): 83-86.

Maivorsdotter, N., and M. Quennerstedt. 2012. "The act of running: a practical epistemology analysis of aesthetic experience in sport." Qualitative Research in Sport, Exercise and Health 4(3): 362-381.

Merriman, P. 2014. "Rethinking mobile methods." Mobilities 9(2): 167-187.

Middleton, J. 2009. "Stepping in time': walking, time and space in the city." Environment and Planning A 41(8): 1943 - 1961.

PHE (Public Health England). 2013. "Obesity and the environment: increasing physical activity and active travel." Gov.uk. Accessed 03 November 2014.

https://www.gov.uk/government/uploads/system/uploads/attachment data/file/256796/Briefin g Obesity and active travel final.pdf

PHE (Public Health England). 2014. "Get everybody active every day." Gov.uk. Accessed 03 November 2014. https://www.gov.uk/government/news/get-everybody-active-every-day

Plymouth City Council. 2012. "South West Coast Path Walking Guide." Plymouth City Council. Accessed 25 November 2014. http://www.plymouth.gov.uk/swcp on 25/

Pooley, C.G., J. Turnbull, and M. Adams. 2005. A Mobile Century? Changes in Everyday Mobility in Britain in the Twentieth Century. Aldershot: Ashgate.

run2work. 2014."Why run2work?" run2work. Accessed 03 November 2014. https://www.run2work.com/about-us/why-run2work/

Sanders-Bustle, L., and K.L. Oliver. 2001. "The role of physical activity in the lives of researchers: A body-narrative." Studies in philosophy and education 20(6): 507-520. 
Seagrave, J.O. 2000. "Sport as Escape." Journal of Sport and Social Issues 24(1): 61-77.

Shaw, J., and I. Docherty. 2014a. "Geography and Transport." In The Routledge Handbook of Mobilities, edited by P. Adey, D. Bissell, K. Hannam, P. Merriman, and M. Sheller, 25-35. Abingdon: Routledge.

Shaw, J., and I. Docherty. 2014b. The Transport Debate. Bristol: Policy Press.

Shaw, J., and M. Hesse. 2010. "Transport, geography and the 'new' mobilities." Transactions of the Institute of British Geographers 35(3): 305-312.

Shipway, R., and I. Holloway. 2010. "Running free: Embracing a healthy lifestyle through distance running." Perspectives in Public Health 130(6): 270-276.

Shipway, R., and I. Holloway. 2013. "Health and the running body: Notes from an ethnography." International Review for the Sociology of Sport. Accessed 27 March 2014. http://irs.sagepub.com/content/early/2013/11/20/1012690213509807.abstract

Shipway, R., I. Holloway, and I. Jones. 2013. "Organisations, practices, actors and events: Exploring inside the distance running social world." International Review for the Sociology of Sport 48(3): 259-276.

Shipway, R., and I. Jones. 2008. "The Great Suburban Everest: An 'Insiders' Perspective on Experiences at the 2007 Flora London Marathon." Journal of Sport \& Tourism 13(1): 61-77.

Sidaway, J. 2009. "Shadows on the path: negotiating geopolitics on an urban section of Britain's South West Coast Path." Environment and Planning D: Society and Space 27(6): 1091-1116.

Simpson, P. 2014. "Video." In The Routledge Handbook of Mobilities, edited by P. Adey, D. Bissell, K. Hannam, P. Merriman, and M. Sheller, 542-552. Abingdon: Routledge.

Smith, G. 2002. "Racing against Time? Aspects of the Temporal Organization of the Runner's World." Symbolic Interaction 25(3): 343-362.

Spinney, J. 2009. "Cycling the City: Movement, Meaning and Method." Geography Compass, 3(2): 817-835.

Spinney, J. 2011. "A Chance to Catch a Breath: Using Mobile Video Ethnography in Cycling Research." Mobilities 6(2): 161-182.

Spooner, H. 2014. "A Kinaesthetic Spirituality: An Autophenomenographic Account of Running $250 \mathrm{~km}$ of the Camino Portugués." Social and Cultural Geography Research Group. Accessed 28 November 2014. http://scgrg.org/wp-content/uploads/2009/09/Spooner-HelenA-kinaesthetic-spirituality-FULL_FINAL-.pdf

Sport England. 2012a "Athletics APS6 results." Sport England. Accessed 22 January 2013. http://www.sportengland.org/research/active people survey/active people survey 6/idoc.as

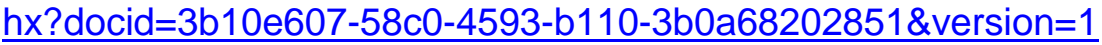

Sport England. 2012b. "Satisfaction with the quality of sporting experience survey (SQSE 4) Results for Athletics: Trends 2009-2012.” Sport England. Accessed 27 March 2014. http://www.sportengland.org/media/110940/athletics.pdf 
Sport England. 2013. "Once a week participation in funded sports amongst people aged 16 years and over (October 2012 - October 2013)." Sport England. Accessed 27 March 2014. http://www.sportengland.org/media/226699/1x30 sport 16-factsheet APS7 final.pdf

Tanio, M. 2012. "Artification of Sport: The Case of Distance Running." Contemporary Aesthetics 4: unpaginated.

Till, K. 2012. "Wounded Cities: Memory-work and a Place-Based Ethics of Care." Political Geography 31(1): 3-14

Townsend, L. 2012. "From marathons to mud running." BBC. Accessed 12 October 2012. http://www.bbc.co.uk/news/magazine-16548236

Tulle, E. 2007. "Running to Run: Embodiment, Structure and Agency amongst Veteran Elite Runners.” Sociology 41(2): 329-346.

Vannini, P, ed. 2009. The Cultures of Alterative Mobilities: Routes Less Travelled. Farnham: Ashgate.

Vettenniemi, E. 2012a. "Prologue: Representations of Running." The International Journal of the History of Sport 29(7): 967-979.

Vettenniemi, E. 2012b. "Epilogue: Going the Extra Mile." The International Journal of the History of Sport 29(7): 1090-1095.

Whelan, G. 2012. "Running Through a Field." Performance Research: A Journal of the Performing Arts 17(2): 110-120.

Winters, C. 1980. "Running." Landscape 24(2): 19-22. 
Figure Captions

\begin{tabular}{|l|l|}
\hline \multicolumn{1}{|c|}{ Figure } & \multicolumn{1}{c|}{ Caption } \\
\hline Figure 1 & The line: running from A to B \\
\hline Figure 2 & The loop \\
\hline Figure 3 & The lollipop \\
\hline Figure 4 & The out-and-back \\
\hline Figure 5 & Channelled running routes \\
\hline Figure 6 & Choosing a side \\
\hline Figure 7 & Stepping down \\
\hline Figure 8 & The slalom \\
\hline
\end{tabular}


Figure 1

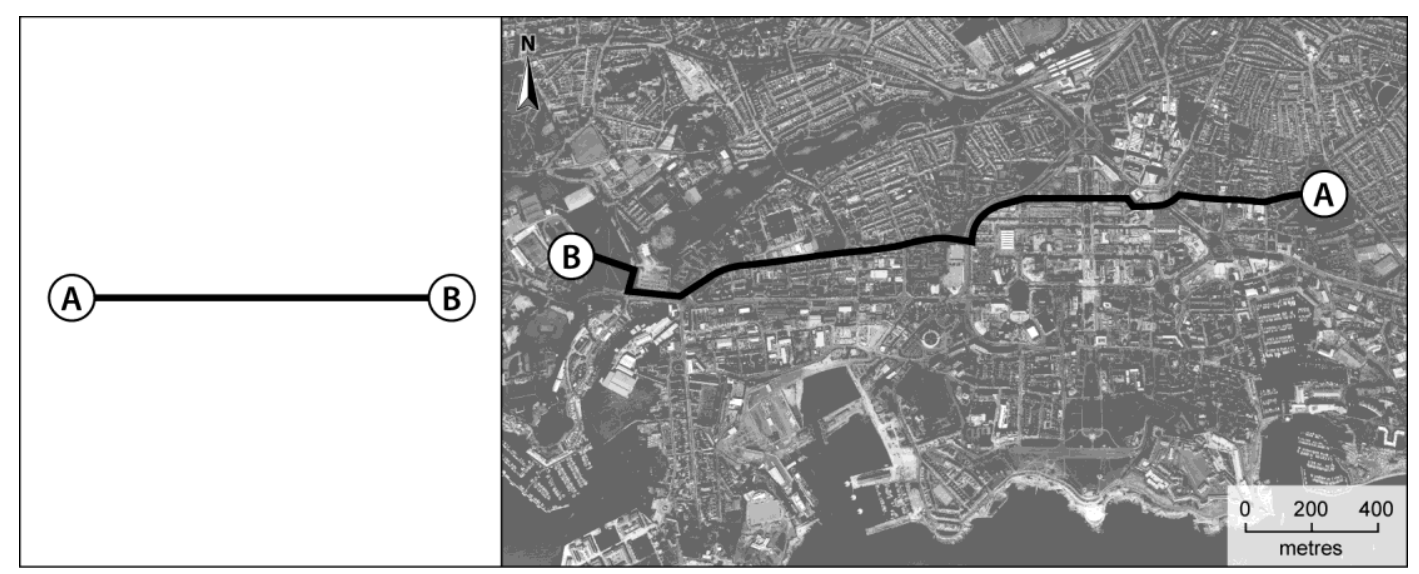


Figure 2

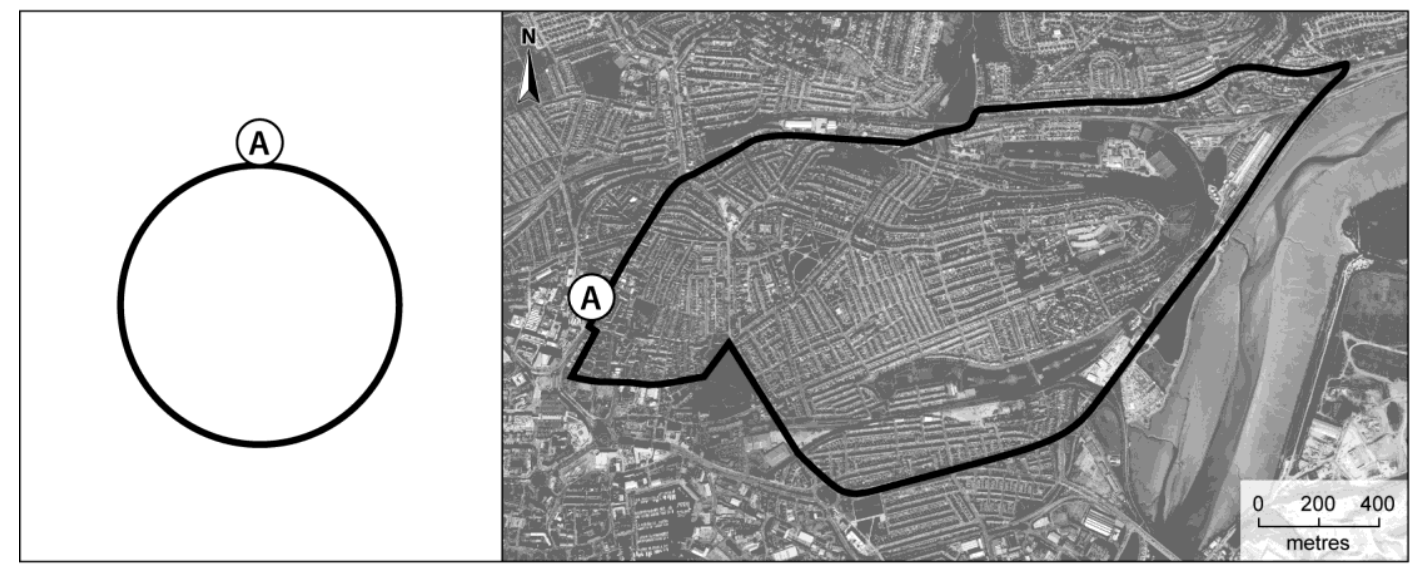


Figure 3

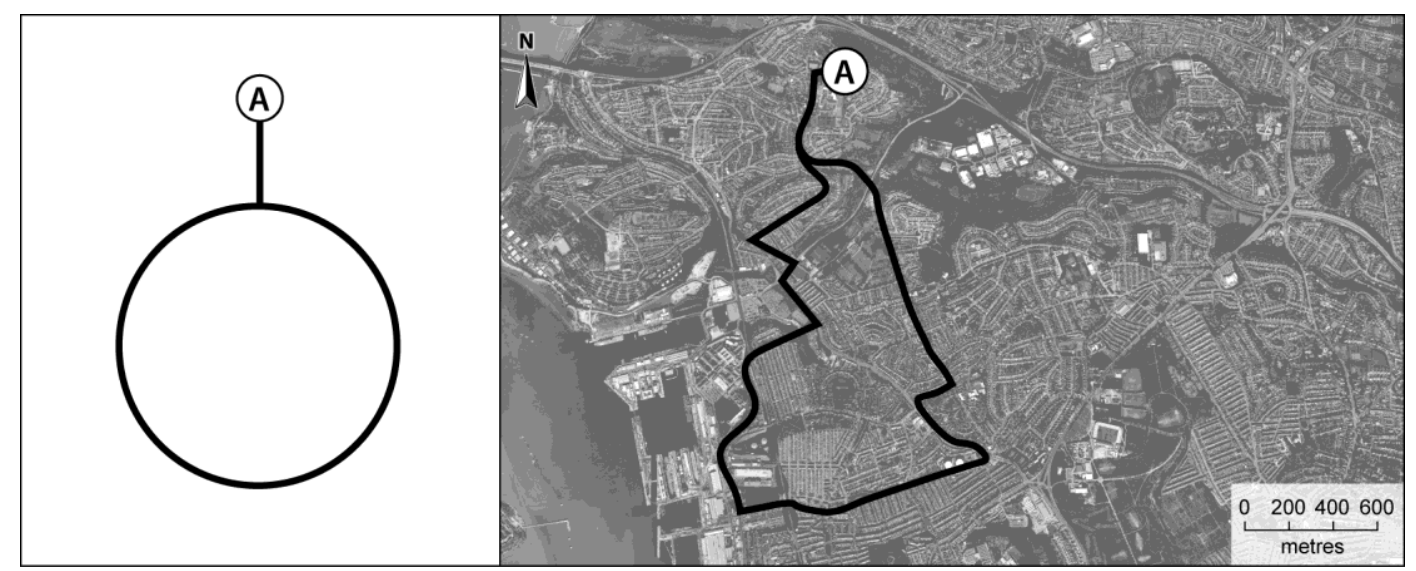


Figure 4

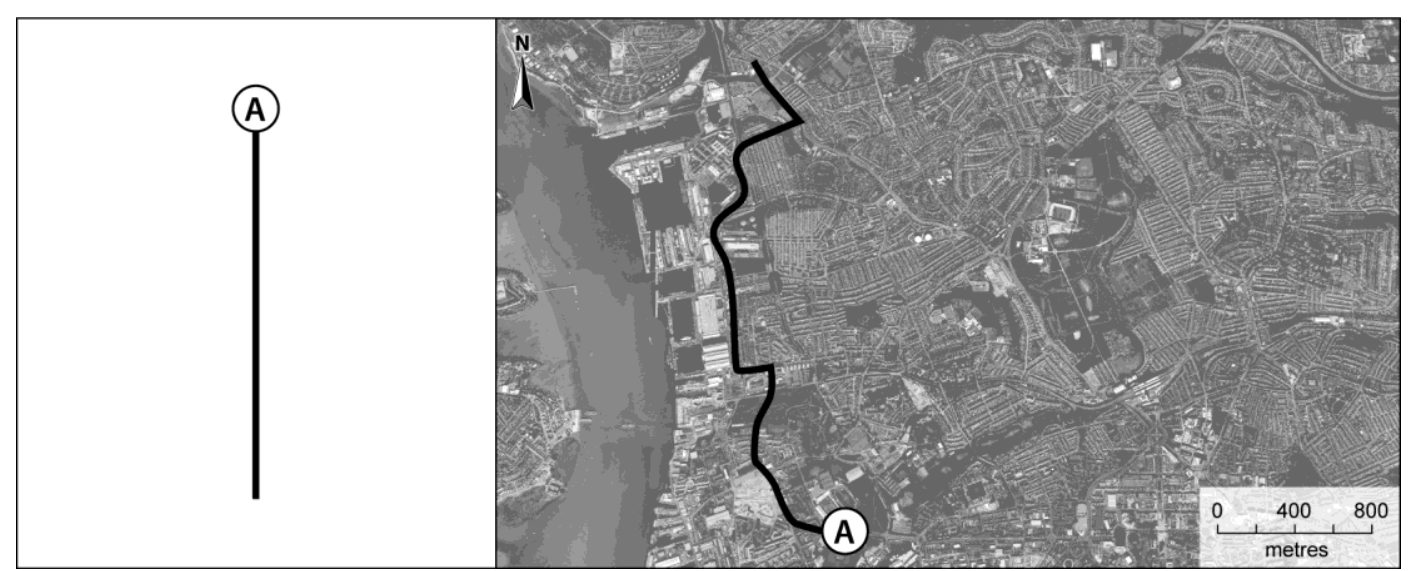


Figure 5

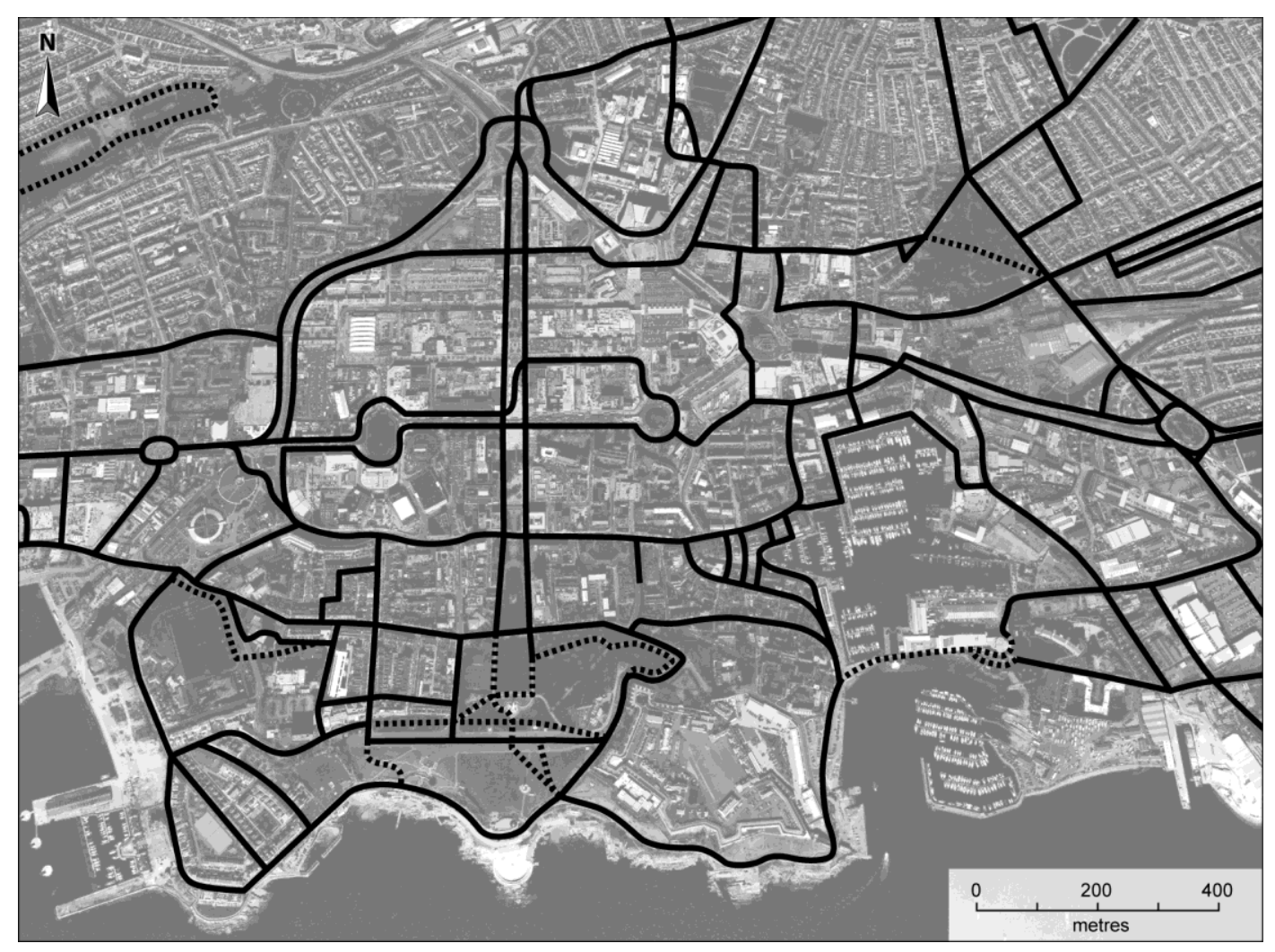


Figure 6
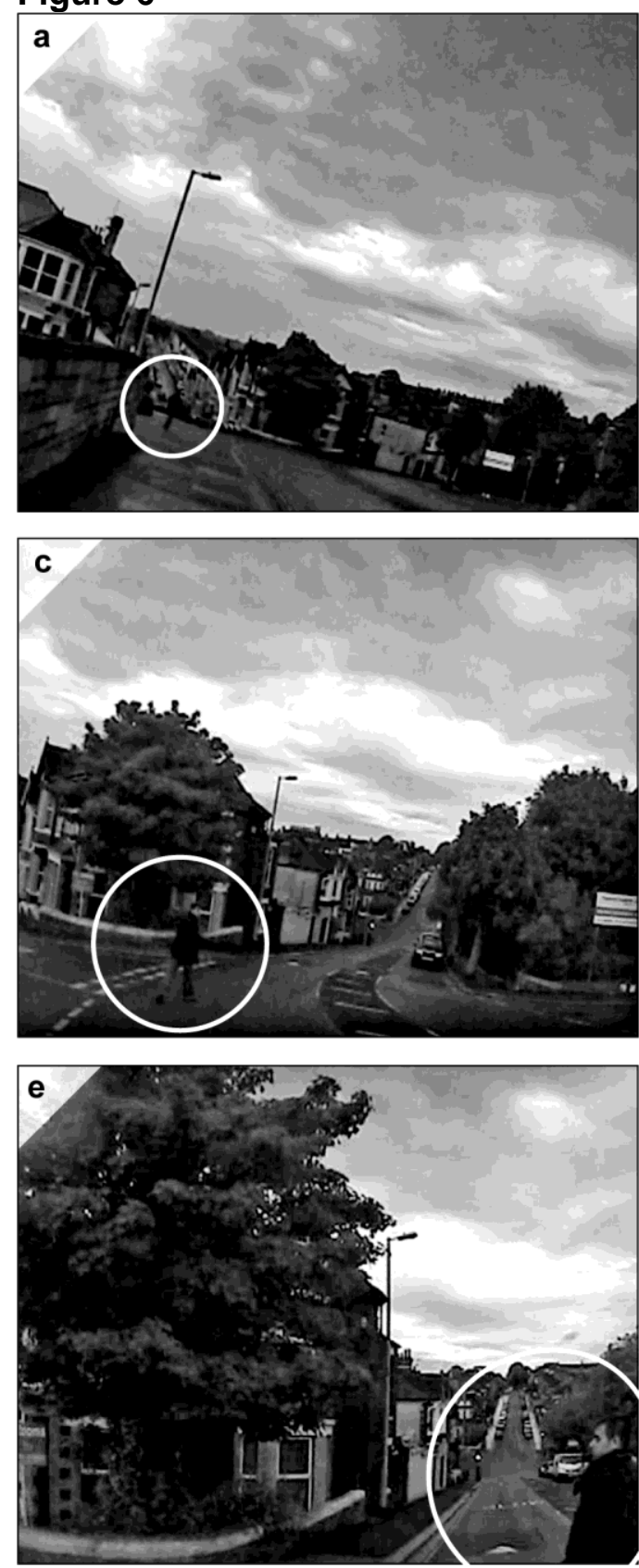
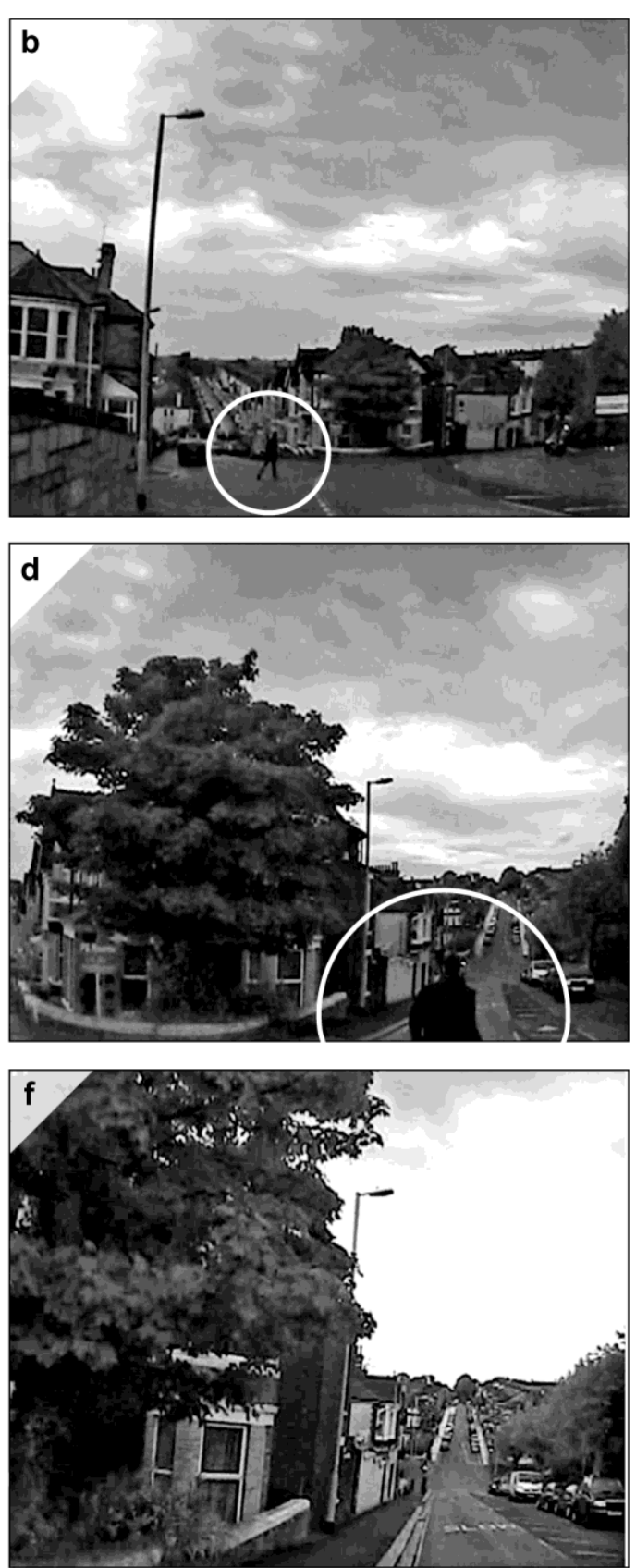
Figure 7
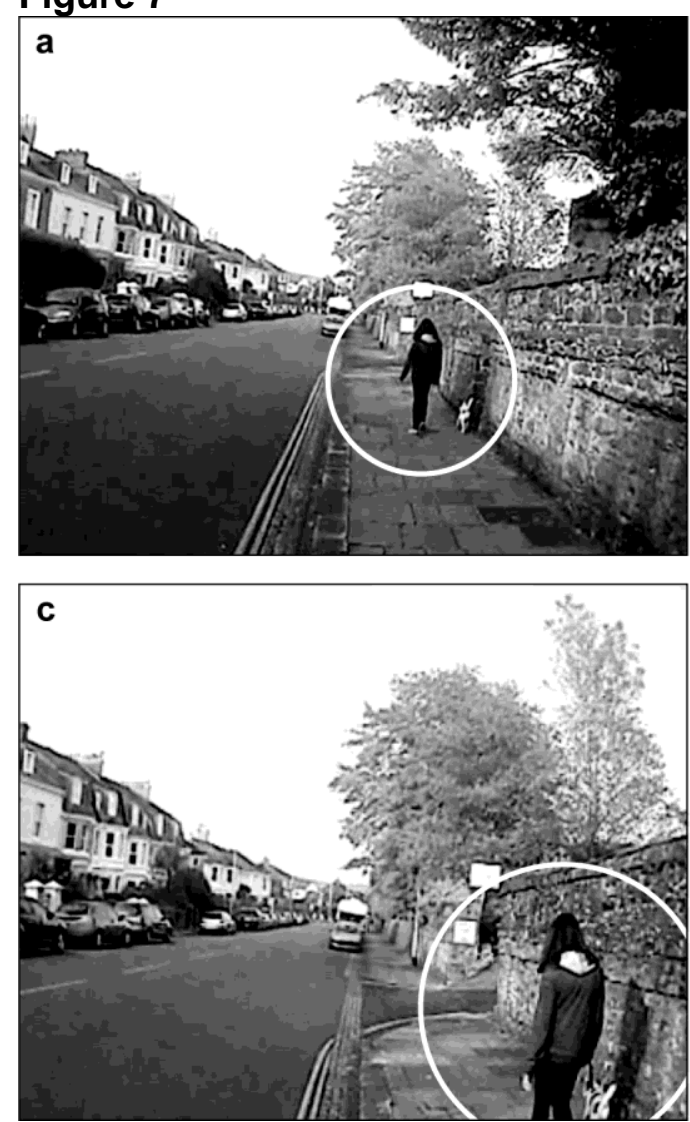
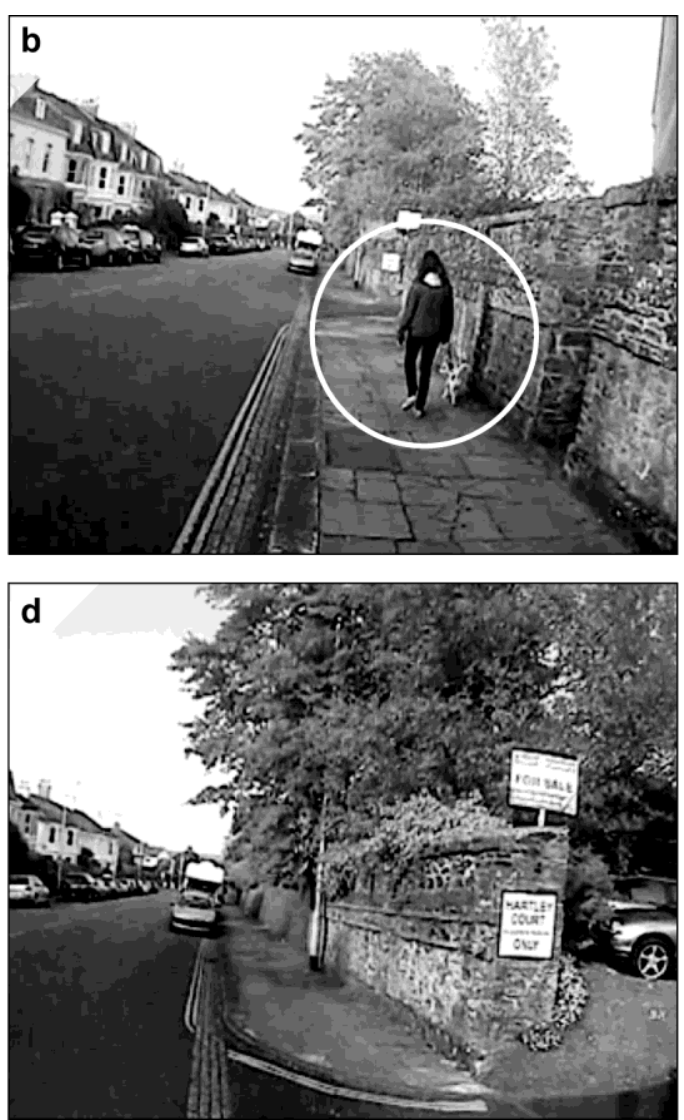


\section{Figure 8}
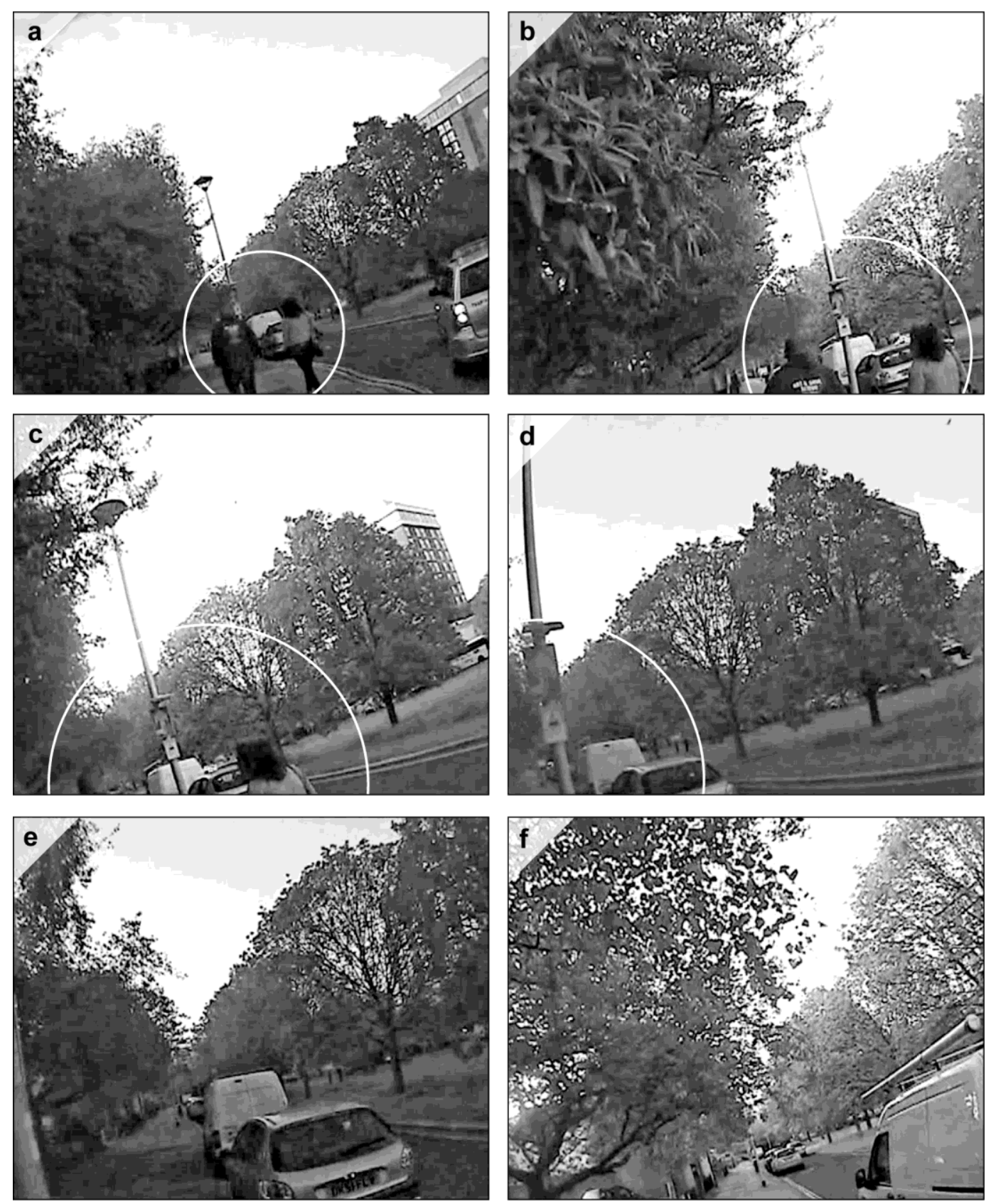